\title{
Dynamic Response Characteristic of Building Structure under Blasting Vibration of underneath Tunnel
}

\author{
Ru He $\mathbb{D}^{1},{ }^{1}$ Nan Jiang $\mathbb{D}^{2},{ }^{2}$ Dong-Wei Li $\mathbb{D}^{1},{ }^{1}$ and Jian-Feng Qi $\mathbb{D}^{2}$ \\ ${ }^{1}$ School of Civil and Architecture Engineering, East China University of Technology, Nanchang 330013, Jiangxi, China \\ ${ }^{2}$ Faculty of Engineering, China University of Geosciences, Wuhan 430074, Hubei, China \\ Correspondence should be addressed to Dong-Wei Li; dwli2005@163.com
}

Received 5 March 2021; Revised 6 June 2021; Accepted 16 December 2021; Published 4 January 2022

Academic Editor: Shan Gao

Copyright $\odot 2022 \mathrm{Ru} \mathrm{He}$ et al. This is an open access article distributed under the Creative Commons Attribution License, which permits unrestricted use, distribution, and reproduction in any medium, provided the original work is properly cited.

\begin{abstract}
The vibration induced by blasting excavation of the subway tunnel in complex urban environments may cause harmful effects on adjacent buildings. Investigating the dynamic response of adjacent buildings is a key issue to predict and control blasting hazards. In this paper, the blasting excavation of the subway tunnel right below a building was selected as a case study, and the blast vibrations in the field were monitored. The Hilbert-Huang Transform (HHT) model was used to extract and analyze the timefrequency characteristic parameters of blasting dynamic response signals. By substituting intrinsic mode functions (IMF) component frequency and instantaneous energy for main frequency and blasting total input energy, respectively, the characteristics of time-instantaneous frequency-instantaneous energy of buildings under blasting seismic load were analyzed, and the concept of effective duration of vibration was proposed.
\end{abstract}

\section{Introduction}

Subway is a key tool to facilitate new urban areas growth and renovate the old urban areas. With the further expansion and encryption of the subway network, the tunnels excavated under the existing buildings will spring up in complex urban environments. The drilling and blasting method, as a costsaving and efficient excavation method for hard-rock tunnel, has been widely used in the excavation of urban metro tunnels. However, the blasting seismic wave will inevitably cause dynamic disturbance to adjacent buildings. Once the construction is not standardized or the vibration control is insufficient, the blasting seismic wave may lead to the cracking or local damage of the building structure. In order to evaluate and control the blasting dynamic damage of buildings reasonably, the dynamic response characteristics of buildings under the blasting vibration of the short-distance underneath tunnel should be evaluated, and potentially dynamic damage should be minimized.

The problem-analyzing perspectives mainly include peak particle vibration velocity (PPV) [1-4], the dominant frequency [5-8], and energy [9], and the safety regulations for blasting (GB6722-2014) stipulates the safety threshold of PPV for adobe houses, civil buildings, commercial buildings, tunnels, etc. Due to the complexity and transient nature of blasting seismic waves, PPV and the dominant frequency cannot reflect the variation characteristics of structural blasting dynamic response in the time domain well and cannot fully meet the needs of practical engineering.

The blasting dynamic response of structure can be considered as the propagation and transformation of blasting energy, so energy can comprehensively express the characteristic of building structure and the complexity of blasting seismic wave. At present, the energy analysis methods of blasting seismic wave mainly include Fourier transform and Hilbert-Huang transform (HHT). The Fourier transform's idea is to decompose signal into the weighted sum of sinusoidal signals, and each sinusoidal signal corresponds to a fixed frequency and a fixed amplitude. Therefore, it is very effective for a stable signal whose frequency does not change with time, but not for the nonstationary signal whose frequency varies with time. For example, the blasting energy based on Fourier transform is a total cumulative energy during the duration of blasting 
vibration, which cannot reflect the specific occurrence time of the maximum energy. The time variation of signal cannot be reflected.

HHT is an adaptive signal processing method with stronger time-frequency properties than Fourier transform and wavelet transform. It is composed of empirical mode decomposition (EMD) and Hilbert spectrum analysis (HSA). As the most important step in HHT, EMD was proposed by Huang in 1998 [10], which can decompose complex signal into a series of intrinsic mode functions (IMF) adaptively according to the characteristics of the given signal itself. It fundamentally breaks through the limitations of Fourier transform and establishes the signal analysis method based on instantaneous frequency for the first time [11]. For the complex transient wave such as blasting seismic wave, HHT transform can more clearly and accurately show the specific distribution of energy at any time and frequency, and accurately depict the signal characteristics at any time.

HHT method is mainly applied to damage monitoring and modal identification of construction in civil engineering [12-14]. Until recently, however, HHT and its variants were gradually introduced into blasting vibration signal analysis, and the instantaneous energy and the instantaneous frequency of blasting seismic wave began to be valued $[15,16]$. Zong et al. [17] studied the blasting seismic wave signal frequency spectrum characteristics and energy distribution of coalmine roadway excavation by the HHT method and EMD. Liu et al. [18] analyzed the instantaneous total energy of the four charge structures of conventional charge, water interval charge at both ends, water interval charge at the orifice, and water interval charge at the hole bottom. Li et al. [19] proposed here an improved HHT method combined with a wavelet packet to extract the energy spectrum feature of a blast wave. By using instantaneous energy spectrum, Yuan et al. [20] analyzed the blasting vibration signals in a lead-zinc mine in south China by three-dimensional Hilbert spectrum, marginal spectrum, and instantaneous energy spectrum, and the results indicate that the blasting frequencies lie mainly within $0 \sim 200 \mathrm{~Hz}$, which consists of more than $90 \%$ of the total signal energy. Chen et al. [21] studied the propagation laws of blasting vibration waves in weak rock tunnels using HHT and found that with a given charge quantity, as the distance from the explosion source increases, the spectrum width of the blasting vibration frequency becomes narrower, and the overall energy is more concentrated. Fei [22] processed blasting vibration signals by the HHT method and analyzed the propagation law of blasting vibration under the ancient ruins. Yang et al. [23] explored the propagation attenuation characteristics of blasting during tunnel excavation in the grade change area of surrounding rock and analyzed the distribution laws of instantaneous energy in time domain and frequency domain. Most of the existing blasting energy studies focus on the analysis of the blasting seismic wave propagation.

The structural blasting dynamic response is not only related to the propagation law of blasting seismic wave but also should consider the working condition and the characteristics of the building itself. Due to diverse architectural features, such as structure types, building stories, foundation types, and construction measures, the blasting seismic wave of the same or similar working conditions used to produce the different structural dynamic disturbance response characteristics. Therefore, it is the key to analyze the blasting dynamic response characteristics of buildings with different structural types, obtain the variation law of the blasting dynamic response characteristics, and enrich the blasting safety regulations. Comparing with other analysis methods, like Fourier transformation and the wavelet, the HHT not only extracts the real information of structural dynamic response in the time domain but also effectively removes noise from monitoring signals. However, it is very rare to use HHT to analyze the instantaneous characteristics of the structural dynamic response signals [24], and the report of time-instantaneous frequency-instantaneous energy study of structural dynamic response under blasting vibration of underneath tunnel is not available yet.

Based on the monitoring data, HHT is introduced into the dynamic response characteristic analysis of multistorey frame structure under blasting vibration of underneath tunnel, using the dominant instantaneous frequency and the instantaneous energy to replace the dominant frequency and the total input energy, respectively, the time-instantaneous frequency-instantaneous energy variation law of multistorey frame concrete building under tunnel blasting excavation is analyzed. The maximum instantaneous energy in the vibration duration and the blasting instantaneous energy at the peak vibration velocity are compared. The curves of horizontal radial, horizontal tangential, and vertical instantaneous energy along the direction of floor height are obtained, respectively. The frequency components and energy contribution percentages of the structural response signals are studied with time. The concept of effective vibration time length is put forward. The concept of effective vibration time length, that is, the duration when the instantaneous energy exceeds a certain limit energy control value in a single blasting, is put forward, which can describe the characteristic law of vibration energy more directly and reliably than the relative duration.

The innovations and main contributions of this paper are described as follows:

HHT is successfully introduced into the analysis of blasting vibration response characteristics of building structures. The effectiveness and superiority of HHT is verified by the analysis and comparison of conventional vibration parameters and instantaneous parameters.

Substituting the IMF component frequency and instantaneous energy for main frequency and total input energy, respectively, the variation law and characteristics of time-instantaneous frequency-instantaneous energy is analyzed. The variation of the main frequency components of the structural response signal and its energy contribution percentage with time is given, which is of great practical values to guide the blasting operations. 
The concept of effective duration of vibration is proposed, which can be defined as the duration when the instantaneous energy exceeds a certain energy control value in a single blasting, and is of great theoretical values to enrich the current blasting safety regulations and the methods evaluating the safety of structures.

\section{Overview of Undercrossing Tunnel Engineering}

The undercrossing tunnel is located between Zhifang Road Station to Qinglongshan Ditiexiaozhen Station of the Wuhan Metro Line 8. The total length of the tunnel is $1274.11 \mathrm{~m}$. This is a single-hole-double-track tunnel with a horseshoe cross section and a size of $11.8 \mathrm{~m} \times 9.6 \mathrm{~m}$ (span $\times$ height). In this project, the tunnel roof is buried at a depth of $15 \mathrm{~m}$. As the tunnel is embedded in rock of high grade, the drilling and blasting method is adopted. The distribution of the underlying stratum is shown in Figure 1(b). There are $3.5 \mathrm{~m}$ thick plain fill, followed by $8.5 \mathrm{~m}$ thick of clay and then moderately weathered limestone from top to bottom.

Right above the tunnel, there is a newly constructed building, which consists of a basement and two above ground levels. As illustrated in Figure 1(a), the tunnel is parallel to the long axis of building.

The building is a kindergarten teaching building. The foundation of the building is pile foundation, and there is a basement, which makes the soil-structure dynamic interaction more obvious and results in stronger dynamic response.

The hard-rock tunnel is constructed by center diaphragm (CD) excavation method using 2\# rock emulsion explosive with the cyclical footage of about $1.5 \mathrm{~m}$. According to the design requirements, a shallow hole millisecond blasting method should be used for the construction of the tunnel, and multiperiod nonelectric millisecond detonators control the explosions.

According to the requirements of the project site, the PPV of the ground surface node should not exceed $2 \mathrm{~cm} \cdot \mathrm{s}^{-1}$. The maximum charge for the same section is $24.57 \mathrm{~kg}$. The single-period charge placed within each cut hole, relief hole, and perimeter hole are $0.8 \mathrm{~kg}, 0.4 \mathrm{~kg}$, and $0.2 \mathrm{~kg}$, respectively. Wedge-shaped cutting is adopted for tunnel excavation. The design depth of the wedge cut eye and the central straight eye is $2.2 \mathrm{~m}$. The diameters of the holes are all $42 \mathrm{~mm}$ and the distance between the cut holes, relief holes, and perimeter holes are $350 \mathrm{~mm}, 400 \mathrm{~mm}$, and $300 \mathrm{~mm}$, respectively.

\section{Blasting Dynamic Response Monitoring Test and Analysis}

The TC-4850 blasting vibration recorder system was used to carry out field monitoring of the blasting vibration response signal of building. The monitoring system consists of a vibration sensor and a vibration recorder. The time-history curve of particle vibration at the monitoring point can be obtained, from which PPV can be extracted, namely, the maximum absolute value of the velocity of particle vibration around the equilibrium position when disturbed by blasting earthquake, as well as the frequency of main vibration, namely, the frequency with the maximum amplitude in the vibration response.

During the test, the blasting vibration test was carried out when the tunnel face was consistent with the short axis of the building. Blasting vibration meters were placed at the outer wall corner, and all measuring points were placed along the height direction. A0, A1, and A2 are vibration measuring points, as shown in Figure 1(b).

The sensor directions were arranged as $X$ direction along the long axis of the building, that is, consistent with the direction of the tunnel, $Y$ direction along the short axis of the building and tangent to the direction of the tunnel, and $Z$ direction was vertical direction.

3.1. Blasting Vibration Characteristics. 12 sets of blasting vibration monitoring data of three measuring points in the building under four times blasting were recorded during the process of excavation blasting of tunnel. The PPV and maximum main frequency recorded for each data set are shown in Table 1. Among them, blasting no. 1 and blasting no. 3 refer to the blasting excavation of the lower bench, while blasting no. 2 and no. 4 refer to the blasting excavation of the upper bench.

Figure 2 shows the variation law of the PPV in the $X$ direction, in the $Y$ direction, and in the $Z$ direction with different heights in the same blasting. The peak response velocity in the $X$ direction $V_{\mathrm{X}}$ and in the $Y$ direction $V_{\mathrm{Y}}$ increases first and then decreases with the increase of floors, which is contrary to the response results of three-story ground buildings without basement in existing studies [25].

The vertical peak velocity $V_{\mathrm{Z}}$ is consistent with the measured results of the response of three-story ground buildings without basement in existing studies [25], showing a trend of decreasing first and then increasing. It can be seen that the basement could make the blasting seismic dynamic response different from that of nonbasement buildings.

Figure 3 shows the variation of the $V_{\mathrm{Z}}$ to $V_{\mathrm{X}}$ ratio and the $V_{\mathrm{Z}}$ to $V_{\mathrm{Y}}$ ratio in the same blasting with the floor. The higher the ratio is, the more obvious the vibration response of the building is in the vertical direction. Different from natural earthquakes, the $V_{\mathrm{Z}}$ to $V_{\mathrm{X}}$ ratio and the $V_{\mathrm{Z}}$ to $V_{\mathrm{Y}}$ ratio are basically greater than 1 under the blasting vibration of tunnel excavation, that is, the vertical PPV is always higher than the horizontal radial and horizontal tangential PPV. In general, the long-axis stiffness of the building is greater than the short-axis stiffness, so the natural vibration frequency building in the vertical direction is closer to the main vibration frequency of the blasting seismic wave.

Figures 3(a) and 3(b) show the ratios of vertical and horizontal PPV decrease from basement to the first floor and increase from the first floor to the second floor. At the 1st floor which has the same elevation with the ground surface, the difference between the vertical and horizontal structural response velocities is the smallest, and the difference between the vertical and horizontal PPV increases with the distance from the ground surface. 


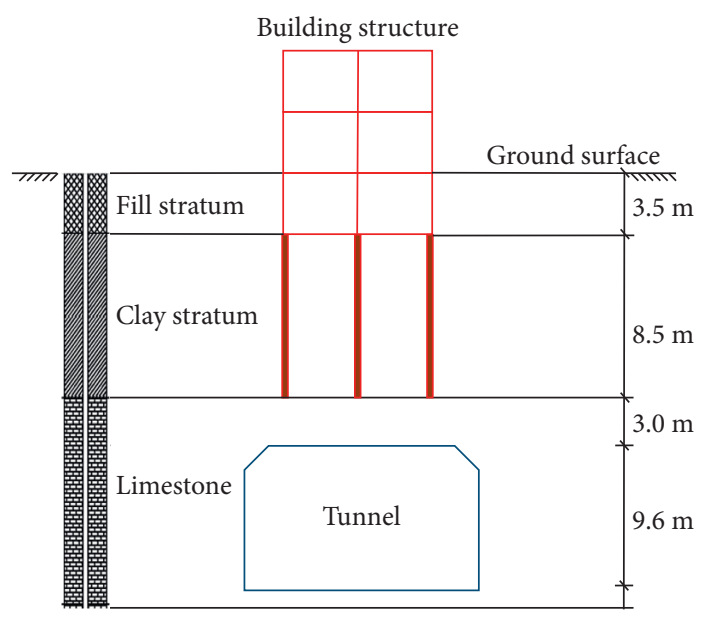

(a)

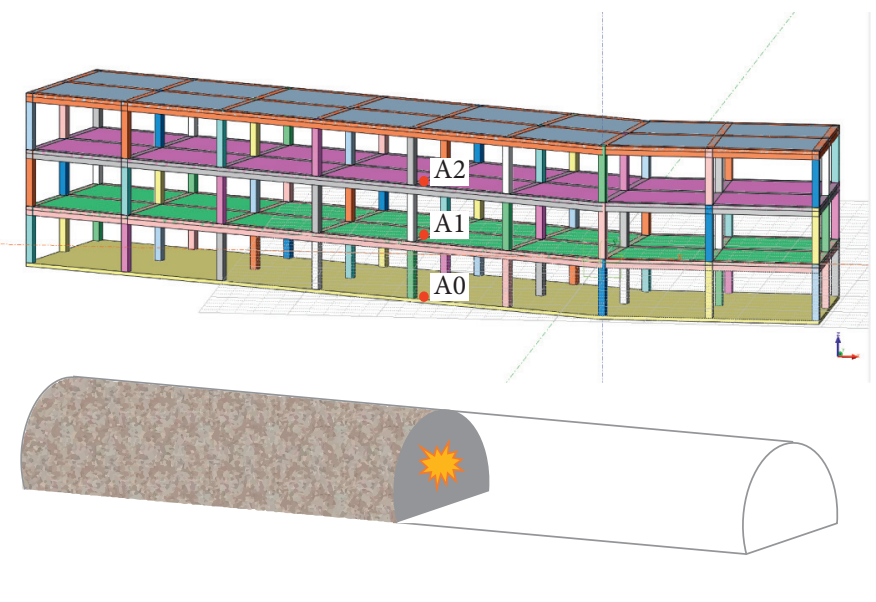

(b)

Figure 1: Positional relationship of the tunnel and building and layout of the monitoring points. (a) Profile graph. (b) 3D graph.

TABLE 1: Vibration monitoring points PPV and maximum main frequency statistics.

\begin{tabular}{|c|c|c|c|c|c|c|c|}
\hline \multirow{2}{*}{ Blasting number } & \multirow{2}{*}{ Vibration measuring point number } & \multicolumn{3}{|c|}{ 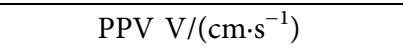 } & \multicolumn{3}{|c|}{ Maximum main frequency $f /(\mathrm{Hz})$} \\
\hline & & $V_{X}$ & $V_{Y}$ & $V_{Z}$ & $f_{X}$ & $f_{Y}$ & $f_{Z}$ \\
\hline No. 1 & A0 & 0.44 & 0.63 & 0.589 & 18.141 & 20.779 & 18.265 \\
\hline No. 1 & A1 & 0.693 & 0.794 & 0.574 & 23.19 & 20.25 & 27.3 \\
\hline No. 1 & $\mathrm{~A} 2$ & 0.572 & 0.652 & 0.702 & 21.68 & 16.33 & 30.2 \\
\hline No. 2 & A0 & 0.70 & 1.872 & 3.79 & 24.54 & 27.304 & 44.944 \\
\hline No. 2 & A1 & 1.592 & 2.812 & 3.341 & 23.6 & 26.94 & 36.7 \\
\hline No. 2 & $\mathrm{~A} 2$ & 1.187 & 3.138 & 5.323 & 16.495 & 22.92 & 34.48 \\
\hline No. 3 & A0 & 1.104 & 2.14 & 4.14 & 38.095 & 24.096 & 11.065 \\
\hline No. 3 & $\mathrm{~A} 1$ & 0.99 & 2.10 & 3.65 & 34.19 & 21.11 & 27.68 \\
\hline No. 3 & $\mathrm{~A} 2$ & 0.605 & 2.29 & 5.96 & 18.78 & 21.56 & 33.06 \\
\hline No. 4 & A0 & 0.44 & 0.69 & 1.58 & 38.84 & 20.31 & 24.77 \\
\hline No. 4 & A1 & 0.50 & 0.70 & 1.185 & 33.33 & 23.39 & 26.23 \\
\hline No. 4 & $\mathrm{~A} 2$ & 0.35 & 0.71 & 1.788 & 23.6 & 23.53 & 29.52 \\
\hline
\end{tabular}

The frequencies of the three main vibration directions of the structure can reflect the dynamic response of building. As shown in Figure 4, the vibration frequency range of the structure response is between $11 \mathrm{~Hz}$ and $44 \mathrm{~Hz}$ subject to the blasting vibration of the underpass tunnel, and the dominant frequency of the speed signal is vertical $>$ horizontal. Under the same blasting, the bandwidths of the dominant frequency band of the velocity response signal in the three directions have the trend that: the first floor $<2$ nd floor$<$ basement. As the floors increase, the main frequencies in the $X$ direction and $Y$ direction gradually attenuate and tend to the natural frequency of the structure, while the main frequency of vertical signal increases with increasing height.

\subsection{Instantaneous Characteristics of Blasting Vibration.} Introducing the HHT analysis method to the analysis of structural dynamic response, the complicated blasting vibration is turned into the combined action of multiple IMF components. Substituting the IMF component frequency and instantaneous energy for main frequency and total input energy, respectively, the variation law and characteristics of time-instantaneous frequency-instantaneous energy is analyzed [26, 27].

Taking the vertical response signals of blasting vibration of the measuring point $\mathrm{A} 0$ in the basement of blasting no. 1 as an example, the variation of its vertical instantaneous frequency, instantaneous amplitude, and instantaneous energy characteristics are analyzed.

The vertical velocity time-history curve is shown in Figure 5(a), and the Fourier frequency spectrum is shown in Figure 5(b). The instantaneous energy and instantaneous frequency time-history curve can be obtained through HHT transformation of the data, as shown in Figures 5(c) and 5(d), respectively.

Figure 5 shows that the dominant frequency of the vertical vibration signal is $18.265 \mathrm{~Hz}$. For the vertical blasting vibration signal, the vertical real-time frequency varies dramatically during the vibration duration, and the instantaneous frequency at the moment of maximum velocity is not consistent with that at the moment of maximum instantaneous energy. Furthermore, the peak time of vibration velocity is not consistent with that of instantaneous energy peak. 


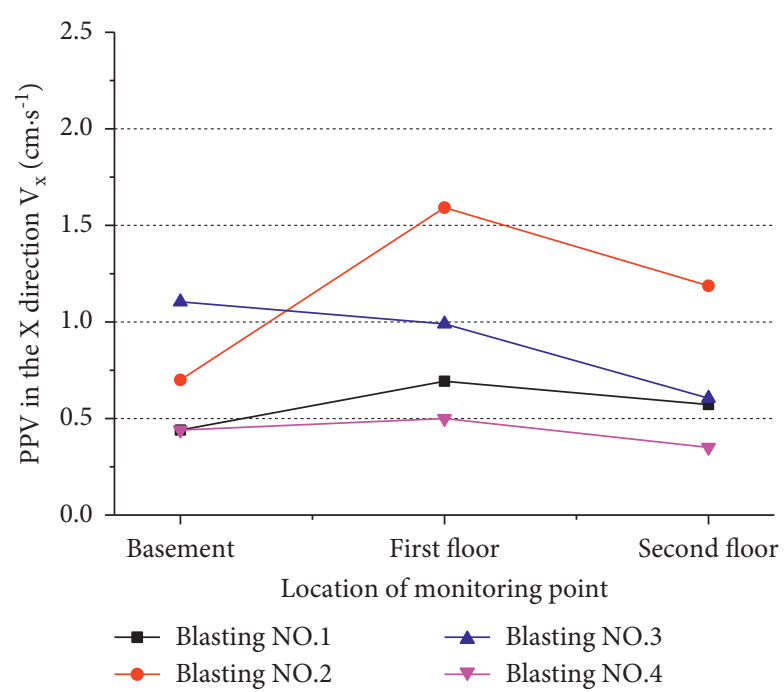

(a)

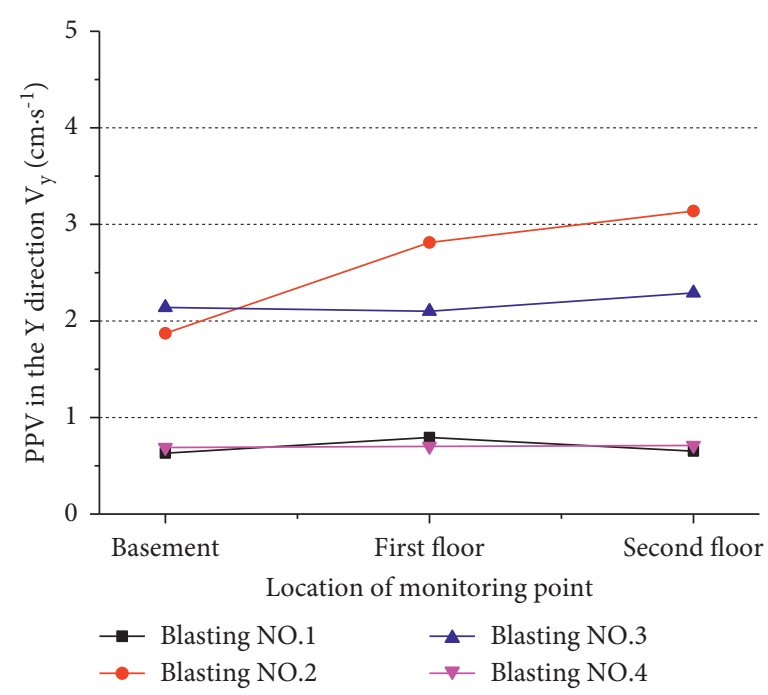

(b)

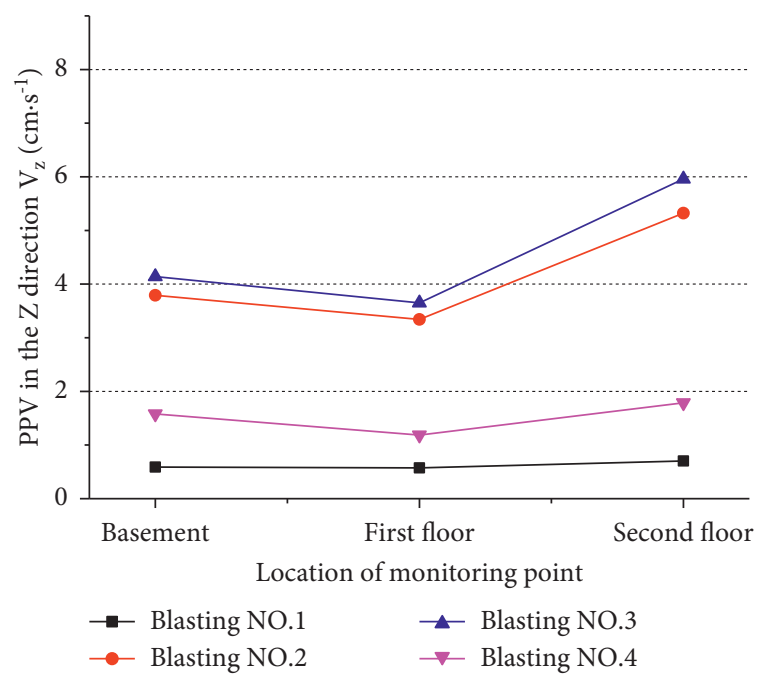

(c)

Figure 2: PPV curves with different heights. (a) PPV in the $X$ direction. (b) PPV in the $Y$ direction. (c) PPV in the $Z$ direction.

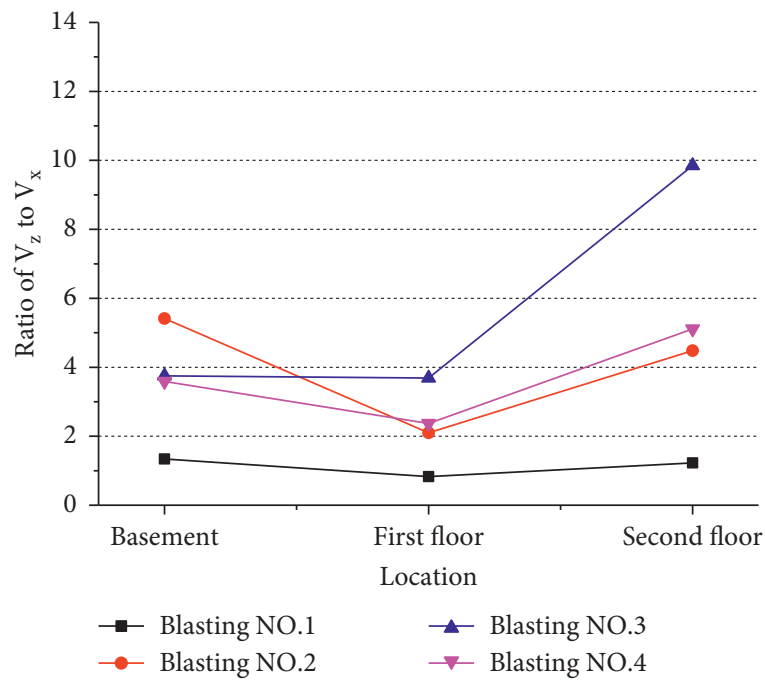

(a)

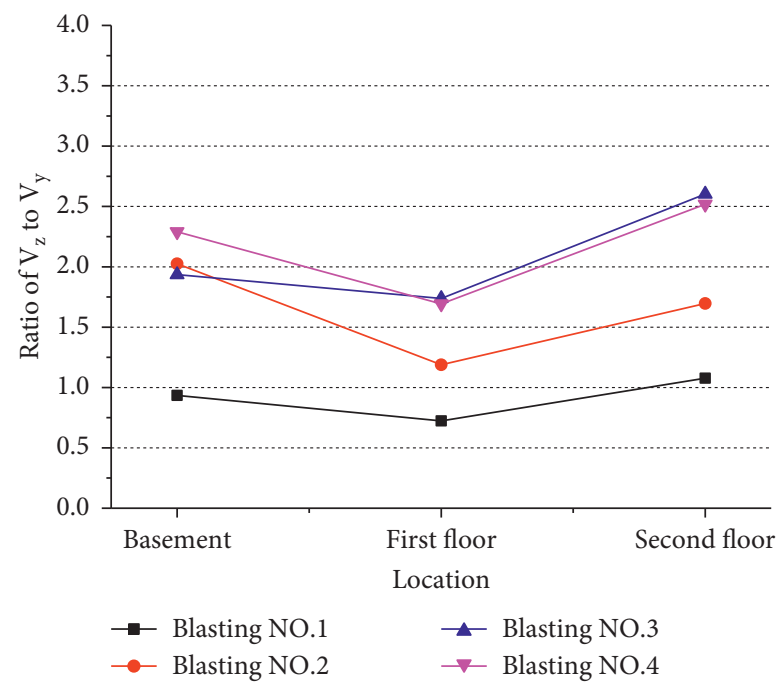

(b)

FIgURE 3: PPV ratio curves with different heights. (a) The $V_{\mathrm{Z}}$ to $V_{\mathrm{X}}$ ratio. (b) The $V_{\mathrm{Z}}$ to $V_{\mathrm{Y}}$ ratio. 


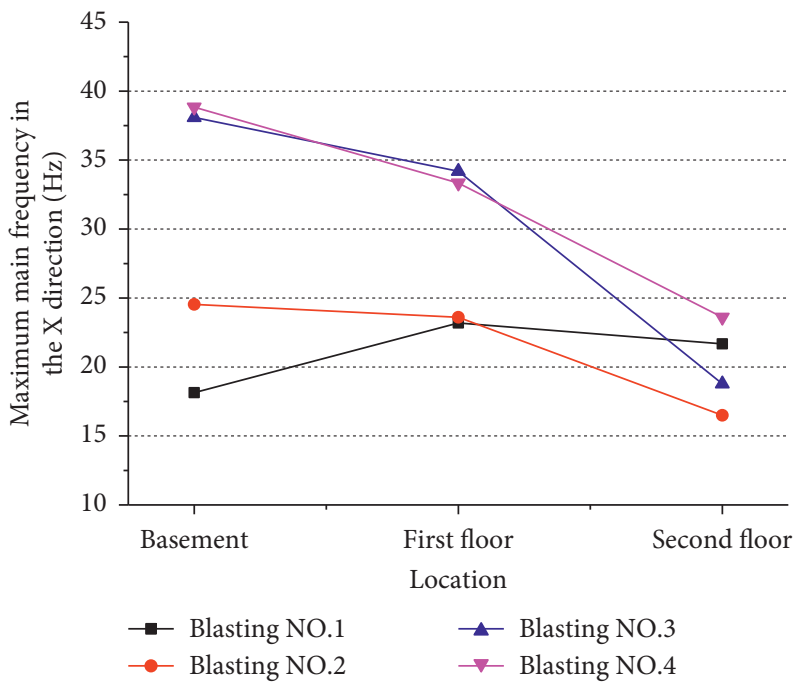

(a)

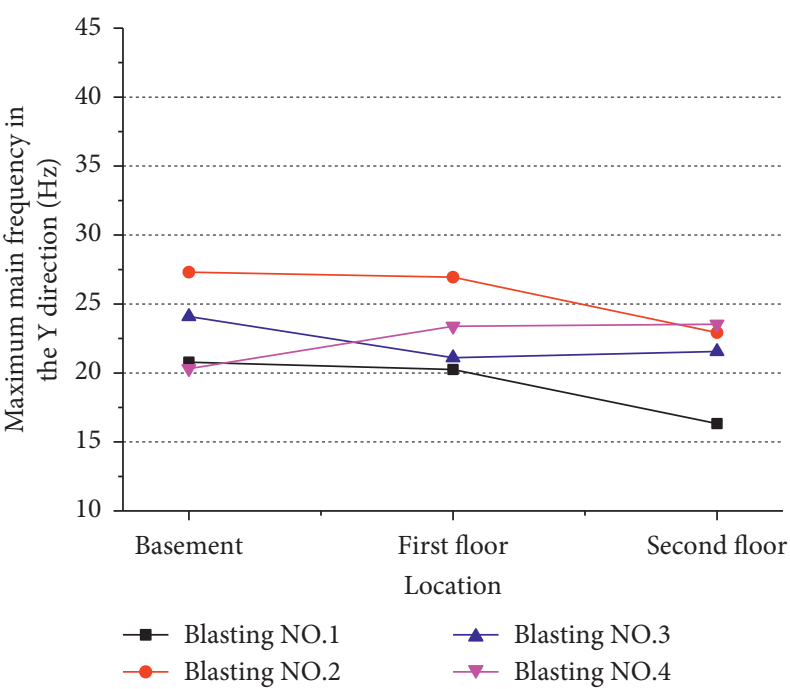

(b)

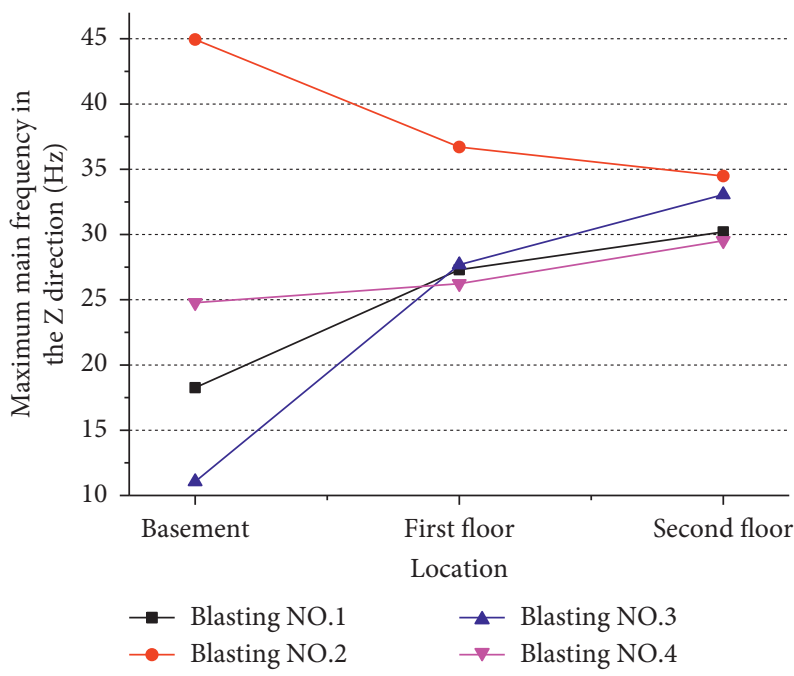

(c)

FIGURE 4: Main frequency curves with different heights. (a) $f_{X-\max }$. (b) $f_{Y-\max }$. (c) $f_{Z-\max }$.

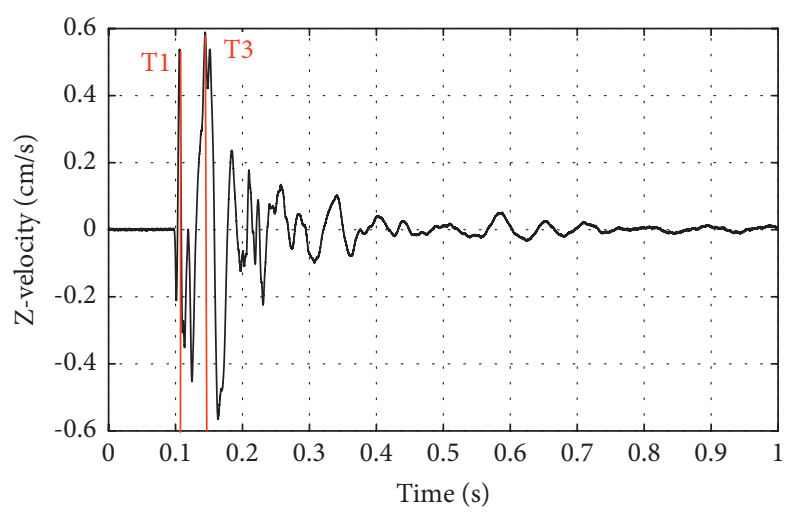

(a)

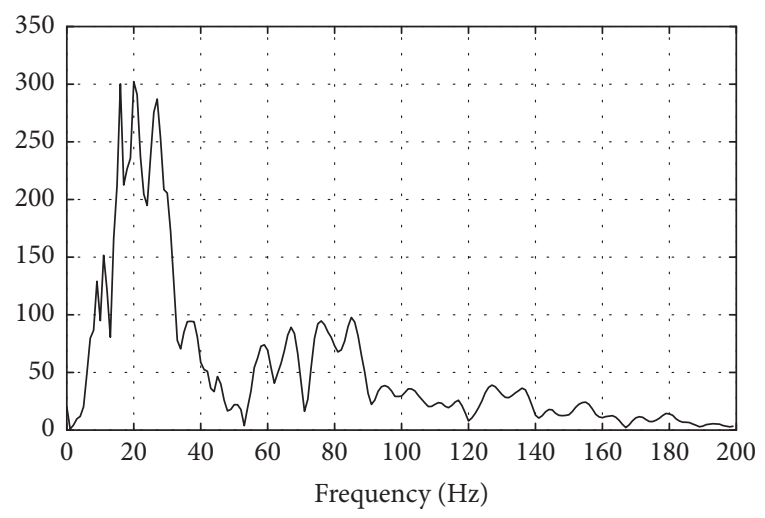

(b)

Figure 5: Continued. 


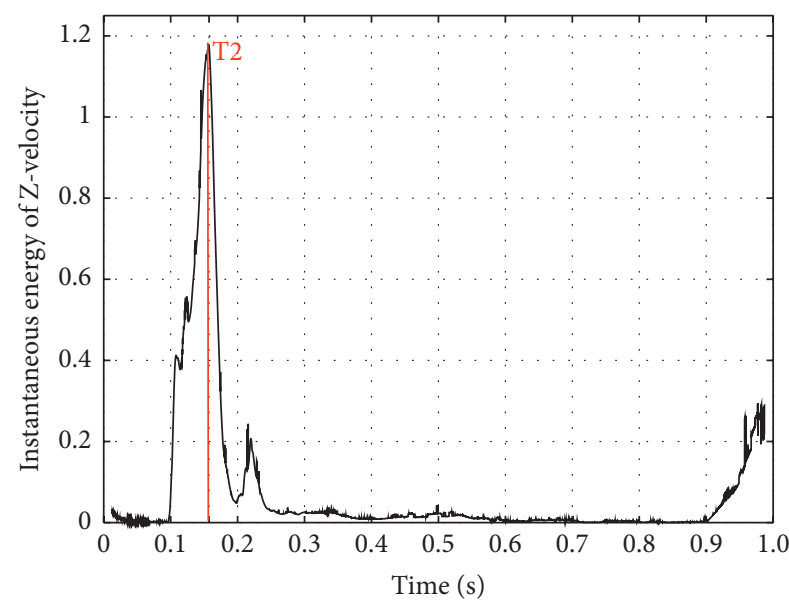

(c)

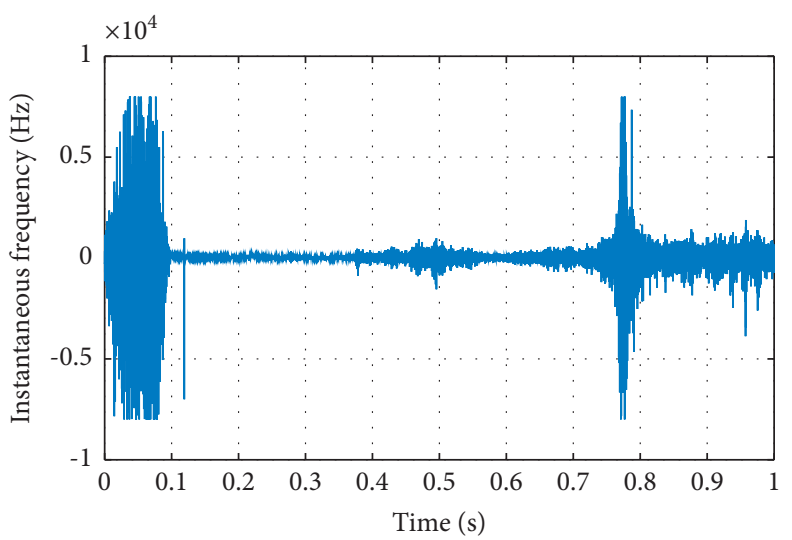

(d)

Figure 5: Vertical response signals of the measuring point A0 of blasting no. 1. (a) The vertical velocity time-history curve. (b) The Fourier frequency spectrum. (c) The instantaneous energy. (d) The instantaneous frequency.

During the vibration process, the particle vibration velocity has two similar peak values, and the instantaneous energy has one peak value. Take the occurrence time of the maximum vibration velocity, the maximum instantaneous energy and the secondary vibration velocity, respectively, as the critical moment $T 1=0.1442 \mathrm{~s}, T 2=0.1573 \mathrm{~s}$, and $T 3=0.1633 \mathrm{~s}$.

The instantaneous energy at the three critical moments is shown in Figure 6. It can be seen that the energy at time T2 is $44.52 \%$ higher than that at time $\mathrm{T} 1$.

By EMD decomposition of vertical vibration velocity signals, 13 IMF components can be obtained. The corresponding instantaneous frequencies and instantaneous amplitudes of the 13 IMF components can be obtained by HHT. The instantaneous frequencies and instantaneous amplitudes at the three critical moments are extracted in Table 2.

As White noise and signal drift, IMF1 and IMF13, have extremely small energy, they are ignored and not included in statistics.

IMF component instantaneous frequency at the three critical moments is shown in Figure 7. According to the analysis and results in Figure 5, the dominant frequency of the vertical vibration signal is $18.265 \mathrm{~Hz}$. Vertical blasting vibration response signals have a rich frequency spectrum, most of which are distributed within $90 \mathrm{~Hz}$, and the dominant frequency spectrum of the signals is within $13.57 \mathrm{~Hz} \sim 20.71 \mathrm{~Hz}$. The IMF components (IMF4 and IMF5) of the intermediate frequency have entered the dominant frequency range of the vertical vibration and are decreasing continuously, which is close to the main frequency $18.265 \mathrm{~Hz}$. The low-frequency IMF components (IMF6 IMF12) enter the range of the structure's natural vibration frequencies $(2 \mathrm{~Hz} \sim 10 \mathrm{~Hz})$. In this region, the instantaneous frequencies of the three critical moments vary slightly around the IMF dominant frequency.

Power spectral density (PSD) defines how to distribute the power of a signal or time series with frequency. The

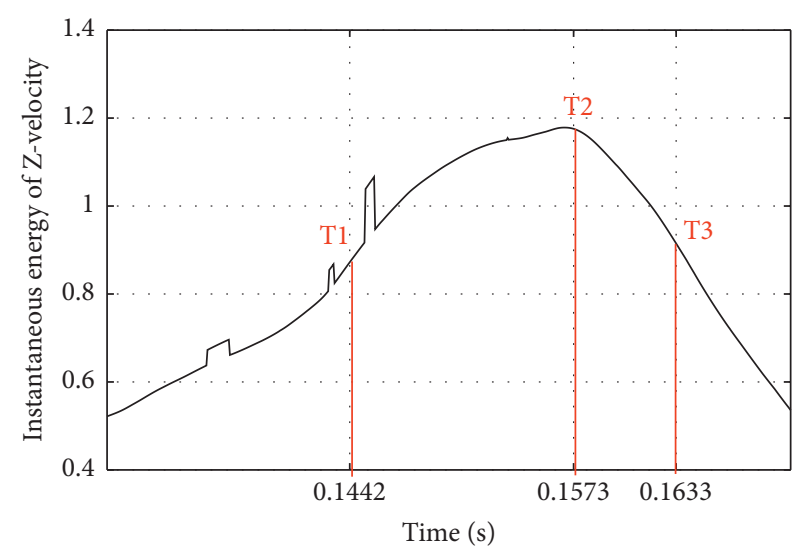

FIgURE 6: Instantaneous energy at the three critical moments.

maximum value of PSD is usually used to represent the important feature information of frequency extracted [28]. According to PSD value of the vertical velocity response signals, its relative advantage in the vertical main frequency band can be shown in Figure 8. Among these IMF components, IMF5 $(20 \mathrm{~Hz}, \quad$ PSD $=275.5), \quad$ IMF8 $\quad(7 \mathrm{~Hz}$, $\mathrm{PSD}=116.88)$, and IMF4 $(58 \mathrm{~Hz}, \mathrm{PSD}=80.43)$ contribute to the vertical dominant frequency significantly.

IMF5, which is closest to the vibration dominant frequency, contributes the most to the dominant frequency. The low frequency IMF8 in the natural frequency range of the component dominant frequency structure has the second contribution. The contribution of intermediate frequency IMF4 cannot be ignored. Especially for the intermediate frequency IMF4, its instantaneous frequency is much higher than the IMF dominant frequency at the three critical moments. In velocity analysis and energy analysis, the dominant frequency of IMF4 cannot replace the instantaneous frequency.

Based on the instantaneous energy spectrum of HHT, the instantaneous energy of each IMF component at three 
TABLE 2: The instantaneous frequency of the IMF component at three critical moments.

\begin{tabular}{|c|c|c|c|c|c|c|c|}
\hline \multirow{2}{*}{ IMF } & \multirow{2}{*}{ Main frequency of IMF $(\mathrm{Hz})$} & \multicolumn{3}{|c|}{ Instantaneous frequency $(\mathrm{Hz})$} & \multicolumn{3}{|c|}{ Instantaneous amplitudes } \\
\hline & & $\mathrm{T} 1$ & $\mathrm{~T} 2$ & $\mathrm{~T} 3$ & $\mathrm{~T} 1$ & $\mathrm{~T} 2$ & $\mathrm{~T} 3$ \\
\hline 2 & 849 & 700 & 1007 & 2891 & 0.001 & 0.0018 & 0.0011 \\
\hline 3 & 131 & 122.77 & 348 & 906.6 & 0.0829 & 0.0009 & 0.0009 \\
\hline 4 & 58 & 137.32 & 76.76 & 92 & 0.0227 & 0.1382 & 0.1064 \\
\hline 5 & 20 & 16.55 & 22.50 & 23.75 & 0.5463 & 0.6408 & 0.5639 \\
\hline 6 & 16 & 17.447 & 20.55 & 22.43 & 0.0211 & 0.0393 & 0.0489 \\
\hline 7 & 15 & 16.77 & 20.5 & 23.82 & 0.0071 & 0.0045 & 0.0038 \\
\hline 8 & 7 & 6.09 & 5.74 & 5.52 & 0.0369 & 0.0436 & 0.0464 \\
\hline 9 & 16 & 2.24 & 1.81 & 0.75 & 0.0019 & 0.00213 & 0.0021 \\
\hline 10 & 7 & 2.79 & 3.32 & 3.64 & 0.0982 & 0.0108 & 0.0113 \\
\hline 11 & 4 & 3.32 & 3.34 & 3.41 & 0.0052 & 0.0051 & 0.0051 \\
\hline 12 & 3 & 2.33 & 2.29 & 2.32 & 0.0059 & 0.0059 & 0.0059 \\
\hline
\end{tabular}

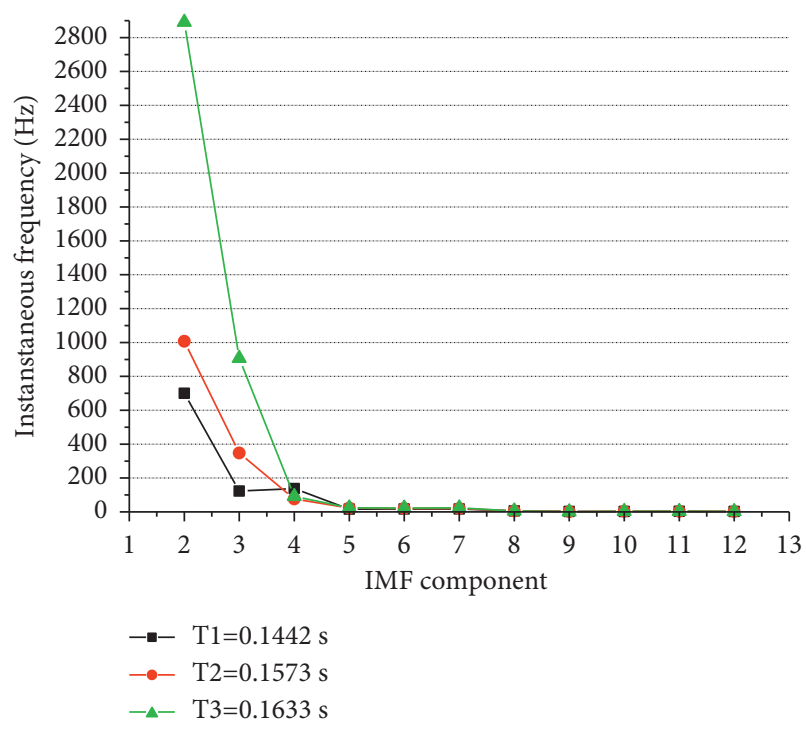

(a)

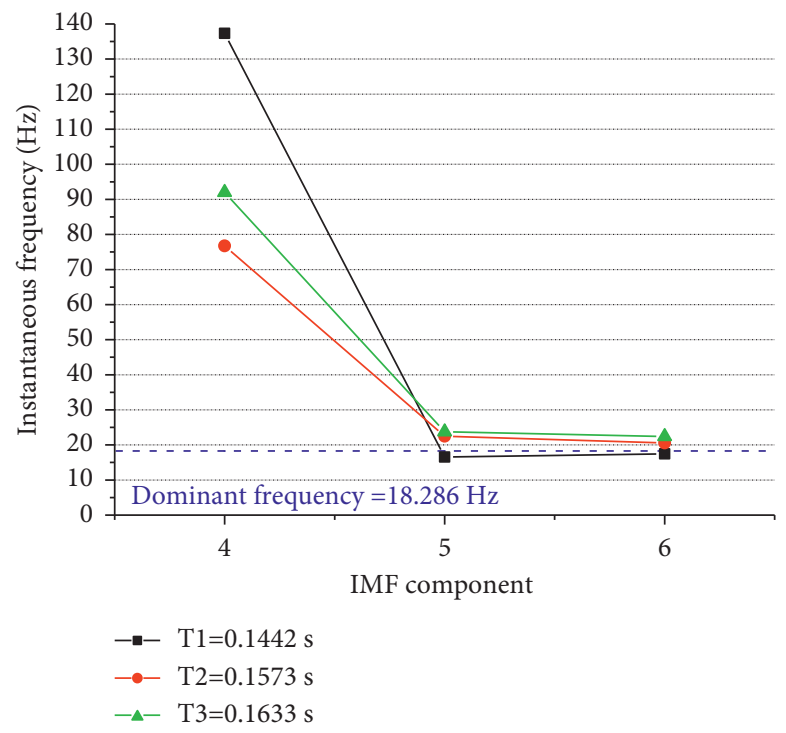

(b)

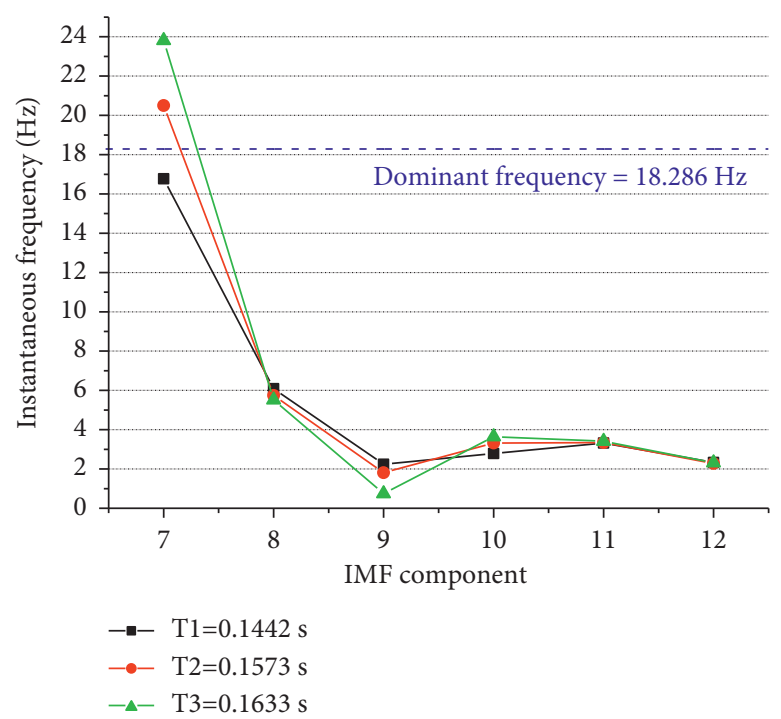

(c)

FIGURE 7: IMF component instantaneous frequency at the three critical moments. (a) Instantaneous frequency. (b) Intermediate instantaneous frequency. (c) Low instantaneous frequency. 


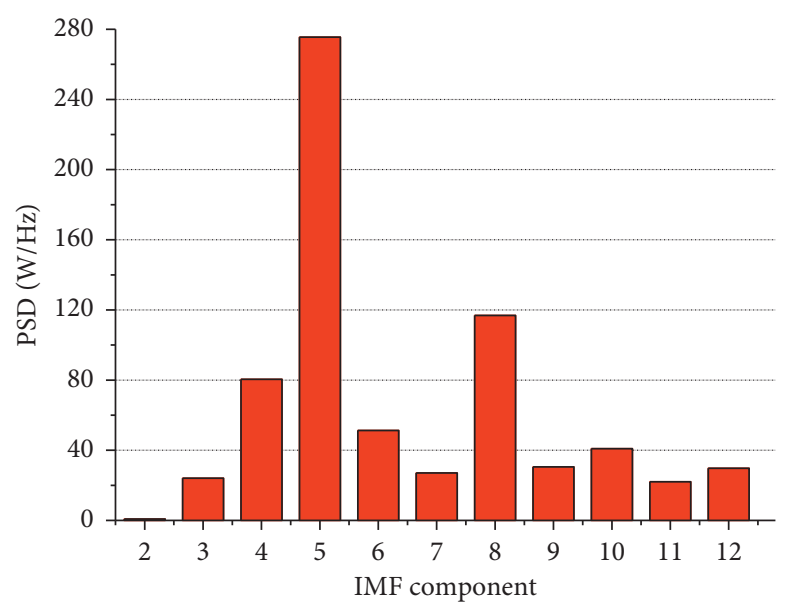

FIgUre 8: The PSD value of IMF component.

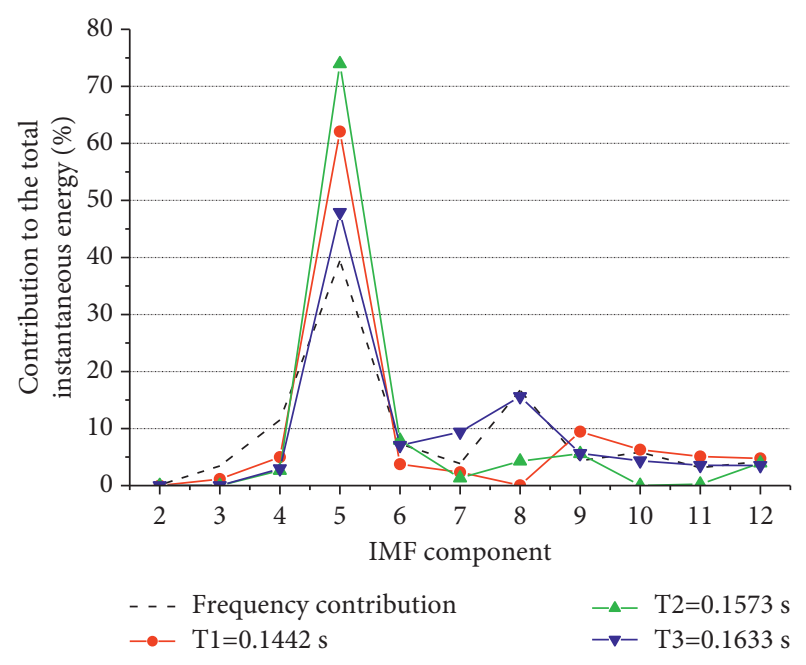

Figure 9: Ratio of IMF instantaneous energy to the total vertical instantaneous energy.

critical moments and its percentage in the total vertical instantaneous energy can be obtained. As shown in Figure 9, the contributions of IMF components to instantaneous energy are inconsistent with the contributions to vertical vibration main frequency at the three critical time points.

The IMF5 has the most obvious effect on the vertical vibration dominant frequency and the maximum instantaneous energy. The main frequency of IMF5 $(20 \mathrm{~Hz})$ is the closest one to the vibration dominant frequency $(18.265 \mathrm{~Hz})$. The IMF component with the second largest energy contribution to the instantaneous energy is not fixed. The second largest energy contribution to $\mathrm{T} 1, \mathrm{~T} 2$, and $\mathrm{T} 3$ is IMF9, IMF6, and IMF8, respectively. The frequency band spans the low frequency and the middle frequency, and the frequency values differ greatly.

3.3. Instantaneous Energy Varies with Different Heights. As mentioned above, the HHT analysis method is used to process 36 sets of data under four blasting, and the variation curves of peak instantaneous energy caused by vibration in $X, Y$, and $Z$ direction along the height are obtained.

As shown in Figure 10, the instantaneous energy curves of $X$ direction and $Y$ direction basically show a trend of increasing first and then decreasing, and the maximum energy appears on the first floor. The instantaneous energy curves in the $Z$ direction are the polar opposite of $X$ and $Y$ direction, that is, the minimum vertical energy occurs on the first floor.

The vibration duration in blasting engineering includes two concepts: single blasting vibration duration and total blasting vibration duration. The duration of single blasting vibration is the duration from the beginning of particle vibration to the complete stop, and the total duration of blasting vibration is the sum of the duration of each blasting vibration.

When blasting seismic wave propagates in a given structure, its input energy constantly transforms between system kinetic energy, system damping energy dissipation, and system deformation energy with the change of time. That is, the maximum instantaneous input energy corresponds to the maximum strain and maximum displacement of the structure.

Therefore, in this paper, consider the maximum instantaneous energy as signs of the first dynamic damage under blasting seismic wave and define the $t_{m-e-z}$ as relative occurrence time of maximum instantaneous energy $\left(\mathrm{E}_{\mathrm{i}-\mathrm{max}}\right)$. The $t_{m-e-z}$ curves of change with the floor are shown in Figure 11.

As can be seen from Figure 11, the occurrence time of the maximum instantaneous energy of each floor varies greatly, and it can appear at $5.7 \%$ of the total vibration duration at the earliest and $97 \%$ of the total vibration duration at the latest.

The influence of vibration duration on building vibration response is mainly in the nonlinear response stage rather than the elastic stage. The impact of vibration duration is mainly manifested in two aspects that are the reduction of elastic limit so that the material can easily enter the plastic state and increase the cumulative damage plastic deformation. 


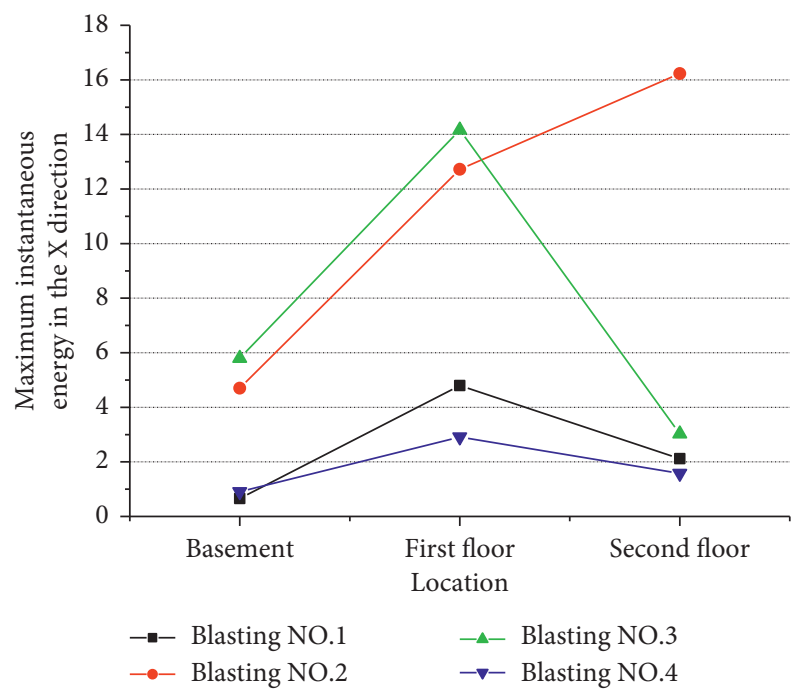

(a)

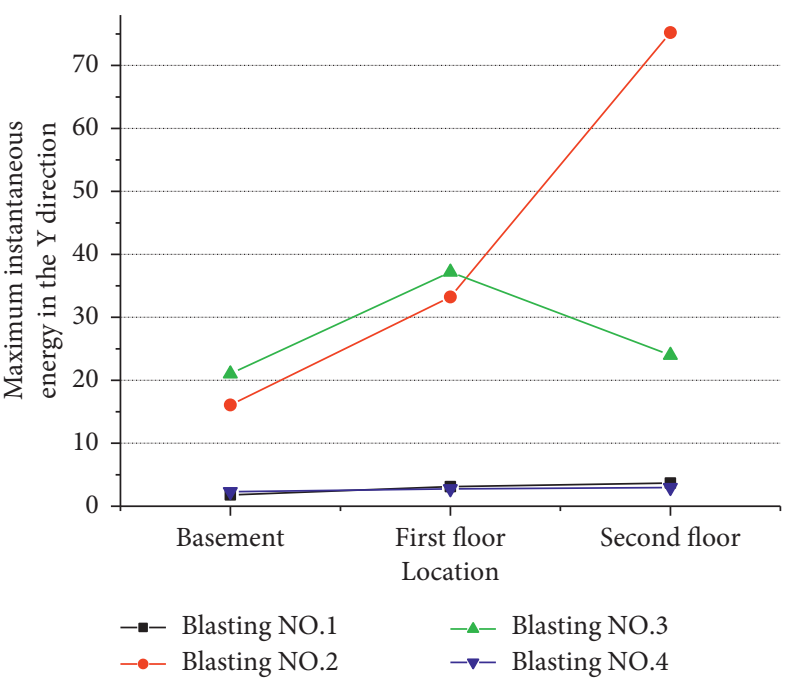

(b)

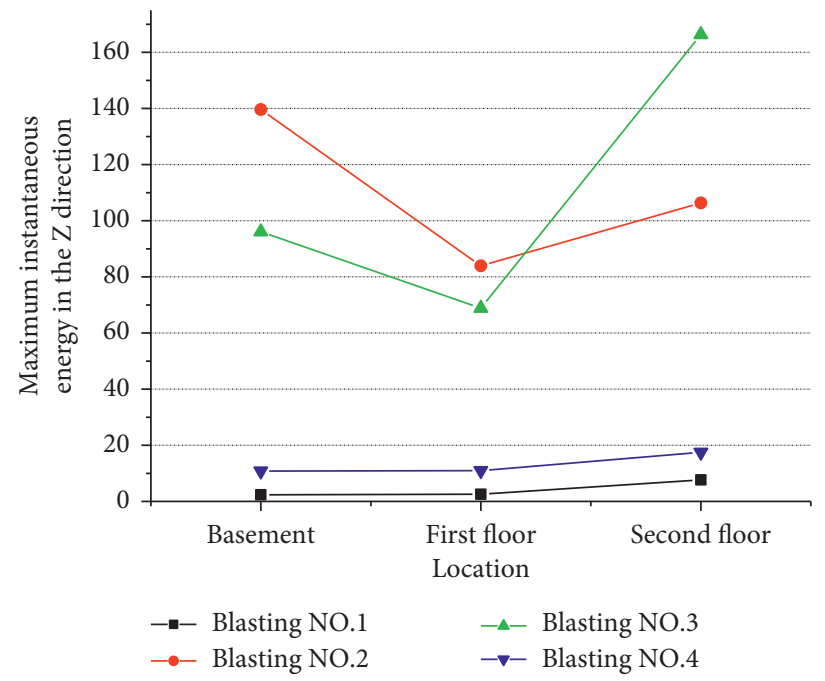

(c)

Figure 10: Maximum instantaneous energy curves with different heights. (a) In the $X$ direction. (b) In the $Y$ direction. (c) In the $Z$ direction.

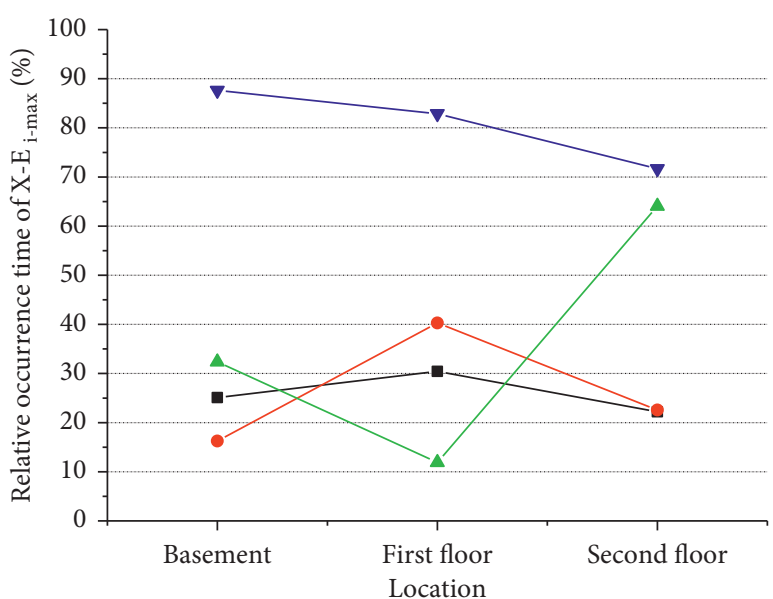

- Blasting NO.1

—— Blasting NO.2

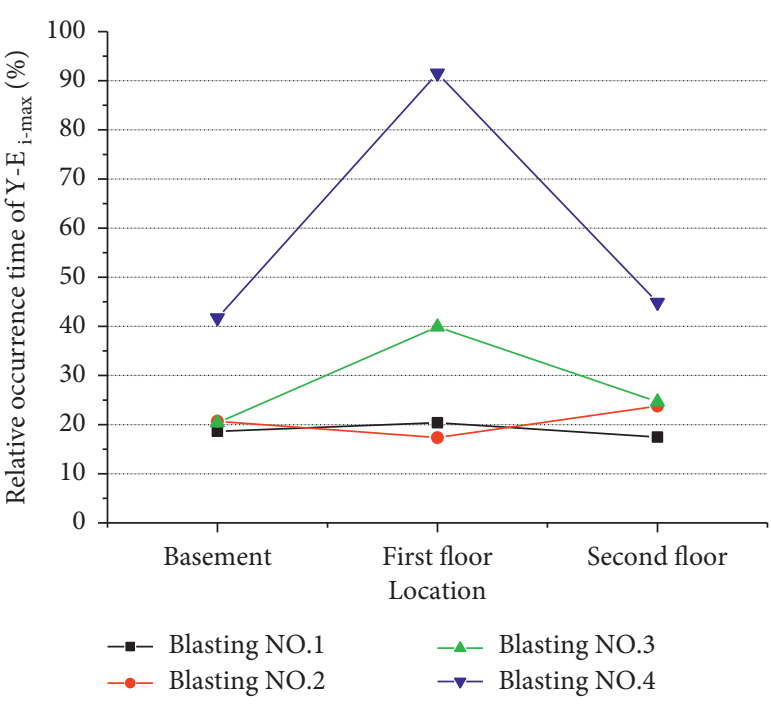

(b)

Figure 11: Continued. 


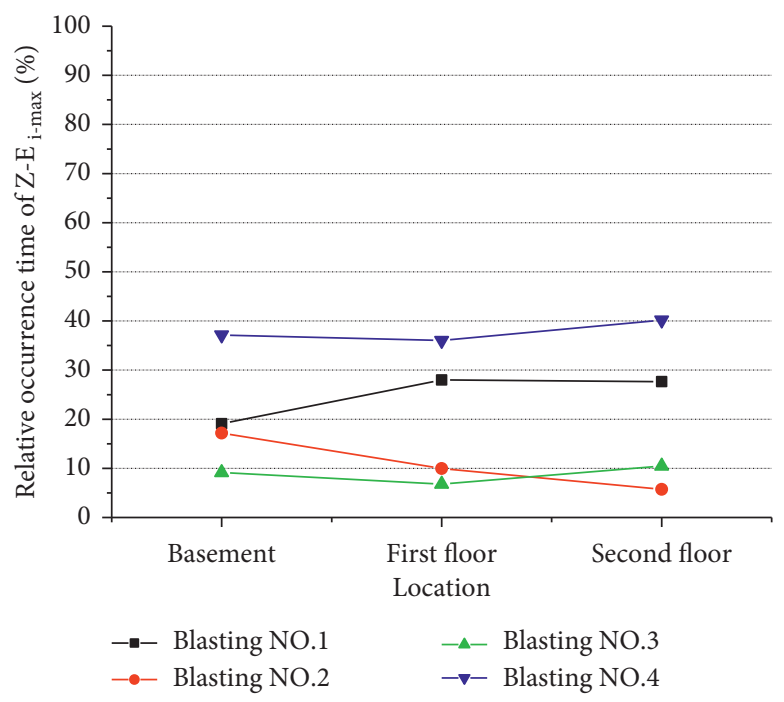

(c)

FIgURE 11: The $t_{\mathrm{m}-\mathrm{e}-\mathrm{z}}$ curves of change with the floor. (a) In the $X$ direction. (b) In the $Y$ direction. (c) In the $Z$ direction.

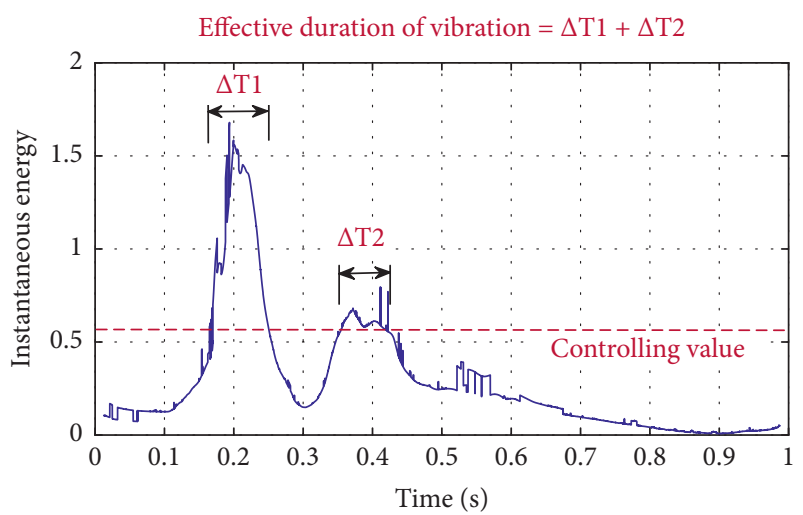

Figure 12: Schematic of effective duration of vibration.

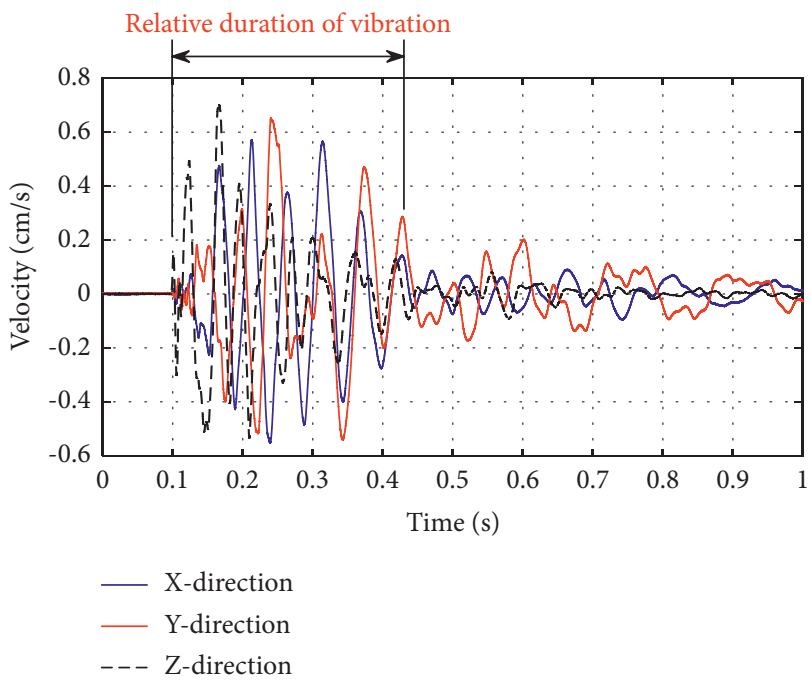

FIGURE 13: Schematic of relative duration of vibration.
Therefore, the duration when the instantaneous energy exceeds a certain energy control value in a single blasting can be defined as the effective duration of vibration in this paper (see Figure 12). Compared with the relative vibration duration, which means the time from the beginning of particle vibration to the time when the amplitude of vibration wave attenuates to $1 / 3$ of its maximum value in actual engineering (see Figure 13). In the dynamic response analysis of the structure, the effective duration of vibration can be more accurate and scientific than the relative duration of vibration. Especially in the study of dynamic response based on instantaneous energy or maximum impulse the effective duration of vibration can describe the characteristic law of vibration energy more objectively and directly than the vibration duration.

\section{Conclusions}

In this paper, a building adjacent to the excavation blasting of underpass tunnel is taken as a case study. Substituting the IMF component frequency and instantaneous energy for main frequency and total input energy, respectively, the variation law and characteristics of time-instantaneous frequency-instantaneous energy is analyzed. The main conclusions are as follows:

(1) Under the blasting vibration induced by undercrossing tunnel excavation, $V_{\mathrm{X}}$ and $V_{\mathrm{Y}}$ increases first and then decreases with the increase of the floor. $V_{Z}$ is firstly decreased and then increased, and $V_{Z}$ is always higher than $V_{\mathrm{X}}$ and $V_{\mathrm{Y}}$. At the 1st floor which has the same elevation with the ground surface, the difference between the vertical and horizontal structural response velocities is the smallest.

(2) The horizontal radial and horizontal tangential instantaneous energy increase firstly and then decrease with the increase of floor under blasting vibration, 
whereas the vertical instantaneous energy variation has the contrary feature.

(3) The instant of maximal peak value of instantaneous energy does not accord with the peak vibration velocity. The frequency and energy contribution of structural response signal change with time and differ considerably from main vibration frequency. Therefore, the main vibration frequency derived from PSD frequency spectrums cannot precisely represent the structural dynamic response under blasting seismic wave.

(4) Effective duration of vibration is defined as the duration when the instantaneous energy exceeds a certain energy control value in a single blasting, which could describe the instantaneous energy or maximum impulse more accurately and effectively in the structure dynamic response analysis under blasting vibration.

Effective duration of vibration is related to the control value of this instantaneous input blasting energy, which is related to the characteristics of the building structure. Due to the diversity of structure, how to effectively link the various parameters of the building structure with the control value of instantaneous input blasting energy is our next work.

\section{Data Availability}

All data included in this study are available upon request by contacting the corresponding author.

\section{Conflicts of Interest}

The authors declare that there are no conflicts of interest regarding the publication of this paper.

\section{Acknowledgments}

This research work was supported by the National Natural Science Foundation of China (Grant nos. 41807265 and 41977236), the Open Research Fund Program of Engineering Research Center of Rock and Soil Drilling and Excavation and Protection of Ministry of Education (Grant no. 202004), and the PhD Funds of East China University of Technology (Grant no. DHBK2019236).

\section{References}

[1] N. Jiang, B. Zhu, X. He, C. Zhou, X. Luo, and T. Wu, "Safety assessment of buried pressurized gas pipelines subject to blasting vibrations induced by metro foundation pit excavation," Tunnelling and Underground Space Technology, vol. 102, Article ID 103448, 2020.

[2] K. Zhao, N. Jiang, C. Zhou, H. Li, Z. Cai, and B. Zhu, "Dynamic behavior and failure of buried gas pipeline considering the pipe connection form subjected to blasting seismic waves," Thin-Walled Structures, vol. 170, Article ID 108495, 2022.

[3] C. Lin, M. Huang, F. Nadim, and Z. Liu, "Tunnelling-induced response of buried pipelines and their effects on ground settlements," Tunnelling and Underground Space Technology, vol. 96, Article ID 103193, 2020.

[4] Y.-Q. Xia, N. Jiang, Y.-K. Yao, and C.-B. Zhou, "Dynamic responses of a concrete pipeline with bell-and-spigot joints buried in a silty clay layer to blasting seismic waves," Explosion and Shock Waves, vol. 40, no. 4, Article ID 043302, 2020.

[5] B. Zhu, N. Jiang, Y.-S. Jia, and C. Zhou, "Field experiment on blasting vibration effect of underpass gas pipelines," Chinese Journal of Rock Mechanics and Engineering, vol. 38, no. 12, pp. 122-132, 2020.

[6] D. Liu, W.-B. Lu, and M. Chen, "Study on the main frequency attenuation formula of blasting vibration of tunnel drilling and blasting excavation," Chinese Journal of Rock Mechanics and Engineering, vol. 37, no. 9, pp. 2015-2026, 2018.

[7] D. Kong, Y. Xu, and C. Song, "Dynamic response of composite steel lining structure under blast loading," Shock and Vibration, vol. 2020, no. 12, 12 pages, 2020.

[8] B. Zhu, N. Jiang, C. Zhou, X. Luo, Y. Yao, and T. Wu, "Dynamic failure behavior of buried cast iron gas pipeline with local external corrosion subjected to blasting vibration," Journal of Natural Gas Science and Engineering, vol. 88, no. 2, Article ID 103803, 2021.

[9] H. Wei, J. Chen, J. Zhu, X. Yang, H. Chu, and X. Liu, “A new zoning method of blasting vibration based on energy proportion and its SVM classification models," Shock and Vibration, vol. 2021, no. 4, 13 pages, Article ID 6697682, 2021.

[10] N. E. Huang, Z. Shen, S. R. Long et al., "The empirical mode decomposition and the Hilbert spectrum for nonlinear and non-stationary time series analysis," Proceedings of the Royal Society of London. Series A: Mathematical, Physical and Engineering Sciences, vol. 454, no. 1971, pp. 903-995, 1998.

[11] C.-Y. Ma, Li Wu, M. Sun, and Q. Yuan, "Time-frequency analysis and application of a vibration signal of tunnel excavation blasting based on CEEMD-MPE-HT," Shock and Vibration, vol. 2021, Article ID 6672942, 2021.

[12] Y.-L. Zhang and R.-X. Li, "Identification of structural parameters based on HHT and NExT," Frontiers Research of Architecture and Engineering, vol. 4, no. 1, 2021.

[13] H. Sun, Q.-R. Si, N. Chen, and S.-Q. Yuan, "HHT-based feature extraction of pump operation instability under cavitation conditions through motor current signal analysis," Mechanical Systems and Signal Processing, vol. 139, Article ID 106613, 2019.

[14] A. A. Mousavi, C. Zhang, S. F. Masri, and G. Gholipour, "Structural damage localization and quantification based on a CEEMDAN hilbert transform neural network approach: a model steel truss bridge case study," Sensors, vol. 20, no. 5, p. $1271,2020$.

[15] X. Li, H. Hu, L. He, and K. Li, "An analytical study of blasting vibration using deep mining and drivage rules," Cluster Computing, vol. 20, no. 1, pp. 109-120, 2017.

[16] G. Hu, H.-L. Fei, S.-J. Bao, and Z.-G. Yang, "Blasting damage accumulative effect of tunnel surrounding rock structure on HHT," Tunnelling and Underground Space Technology, vol. 16, no. 1, pp. 249-259, 2020.

[17] Q. Zong, H.-B. Wang, Y. Xu, and J.-G. Fu, "Coalmine roadway excavation blasting seismic wave signal analysis based on HHT method," Journal of Vibration and Shock, vol. 32, no. 15, pp. 6-120, 2013.

[18] J.-C. Liu, W.-X. Gao, and J. Jiang, "Vibration signal analysis of water seal blasting based on wavelet threshold denoising and HHT transformation," Advances in Civil Engineering, vol. 2020, no. 1, 14 pages, Article ID 4381480, 2020. 
[19] L. Li, F. Wang, F. Shang, Y. Jia, C. Zhao, and D. Kong, "Energy spectrum analysis of blast waves based on an improved Hilbert-Huang transform," Shock Waves, vol. 27, no. 3, pp. 487-494, 2017.

[20] H. Yuan, X. Liu, Y. Liu, H. Bian, W. Chen, and Y. Wang, "Analysis of acoustic wave frequency spectrum characters of rock mass under blasting damage based on the HHT method," Advances in Civil Engineering, vol. 2018, Article ID 9207476, 8 pages, 2018.

[21] L. Chen, J. Chen, Y. Luo et al., "Propagation laws of blasting seismic waves in weak rock mass: a case study of muzhailing tunnel," Advances in Civil Engineering, vol. 2020, no. 9, 15 pages, Article ID 8818442, 2020.

[22] Y.-P. Fei, "Prediction model and safety limit of tunnel blasting vibration under the ancient ruins," Engineering Blasting, vol. 26, no. 5, pp. 42-51, 2020.

[23] Z.-G. Yang, Y.-P. Fei, and G. Hu, "HHT analysis on influence of blasting vibration during tunnel excavation on surrounding rock," Journal of Safety Science and Technology, vol. 15, no. 9, pp. 121-127, 2019.

[24] Z.-S. Wu, Q. Liu, Q.-p. Hou, and Z.-T. Li, "Study on impacted parameters of blasting vibration on brick concrete structure based on HHT method," Chinese Journal of Underground Space and Engineering, vol. 15, pp. 449-453, 2019.

[25] S.-H. Chen, H.-X. Wei, R.-Q. Du, and A.-K. Zhang, Analysis of Blasting Seismic Effect of Building Structure, China Coal Industry Publishing House, Beijing, China, 2011.

[26] N. E. Huang and N. O. Attoh Okine, The Hilbert-Huang Transform in Engineering, CRC Press, Boca Raton, FL, USA, 2005.

[27] N. E. Huang and S. S. P. Shen, Hilbert-huang Transform and its Applications, World Scientific Publishing Company, Singapore, 2nd edition, 2014.

[28] H.-M. Zhao, H.-D. Liu, Y. Jin, X. Dang, and W. Deng, "Feature extraction for data-driven remaining useful life prediction of rolling bearings," IEEE Transactions on Instrumentation and Measurement, vol. 70, Article ID 3511910, 2021. 